\title{
'Sometimes the whole map is red': applying geographical assessment methods to safeguard adolescents from harm in communities
}

Purpose: To explore the opportunities of geographical child protection assessment methods for adolescents victimised in extra-familial contexts.

Design: Presenting empirical evidence from an action research study within one child protection service in the UK, the study draws upon qualitative data from practice observations, case review, training and five context assessments.

Findings: Safety mapping and neighbourhood observations provide options to assess extra-familial contexts. Findings reveal that these methods support practitioners to build local knowledge of areas supporting interventions into community places rooted in principles of child protection.

Practical implications: The article highlights the need for further testing of contextual safeguarding approaches and policy guidance that outlines whose role it is to protect children in communities.

Social implications: Geographical assessment methods provide a route to engage with young people's lived experience of place. And develop interventions that target contexts and not just individuals affected by extra-familial harm.

Originality: The article presents original research into the use of geographical assessment methods to be used within a child protection framework.

Keywords: Adolescents; Child Protection; Child sexual exploitation; extra-familial harm; Mapping; Safeguarding; Serious Youth Violence

\section{Introduction}

In 2018 the UK National Health Service reported a 63\% increase in children treated for stab wounds (The Telegraph 2018). Many of these incidents took place in the neighbourhoods children spend time; on the street, in parks or outside their school (Pitts 2013). These locations, however, are not traditionally associated with child protection whose work predominantly focusses on safety within the home (Department for Education 2018). If 
children encounter harm outside the home, and it is social worker's jobs to protect them, practitioners need methods to identify harm where it happens.

In England, child protection systems focus predominantly on abuse within the home (Munro 2011). In practice this means social workers use assessment frameworks and methods focussed on children and their families. This might include visiting the home and family, interviewing the young person and their parents and observing interactions between parent and child (NSPCC 2015). Yet social work professionals suggest these systems are not fit to consider extra-familial harm (Munro 2011). While there are agencies tasked to work in these spaces - such as community safety partners - the focus of this work is not always child welfare. As such, internationally there are calls to develop child protection systems that account for locations beyond the home (Featherstone, Broadhurst, and Holt 2011).

Here I present the opportunities for using geographical assessment methods. Using data captured in one Children and Families social care department I explore the development of two research methods - safety mapping and neighbourhood observations - as part of developing and embedding a Contextual Safeguarding (Firmin 2017) approach to extrafamilial harm. I argue that utilising geographical assessment methods from a child protection, rather than purely community safety approach, expands the opportunity to understand the spatially contingent nature of abuse from young people's lived experiences of space.

\section{Analytical approach and definitions}

Within this article I use three terms - space, place and context. Space, refers to the physical and social landscapes operating at different temporal and spatial scales (Merrifield 1993). Using Soja's (1996) third space I conceptualise space as both material 'perceived space', seen as physical and mappable, and 'conceived space' (Lefevbre, 1991), imagined geographical spaces that are symbolic and representational. Third space is 'simultaneously 
real and imagined', it is 'lived space' (Soja, 1999, p. 74). Places, are forms of space, imbued with meaning through the activities ascribed by people (Tuan 1979). Finally, Context refers to social fields defined by rules and values which govern social interactions (Bourdieu, 1990). Within Contextual Safeguarding, contexts predominantly refer to a young person's familial, peer, school and neighbourhood context.

This article uses an analytical approach informed by Contextual Safeguarding. Contextual Safeguarding argues that family-focussed child protection models do not adequately respond to harm when it occurs outside the home. When children encounter harm in extra-familial spaces the methods predominately used by social work practitioners to assess harm and intervene are not capable of eliciting information about the relationship between the context and harm. Instead they largely focus on assessing the individual young person and their family.

Instead Contextual Safeguarding requires child protection systems to address four key domains: that the target of child protection systems is the context where harm occurred; the legislative framework used is grounded within child welfare, the partnerships established are those who manage or have influence over the target context, and that outcomes are measured through a change to a context rather than an individual (Firmin 2017). While Contextual Safeguarding entered into England's statutory guidance in 2018 (Department for Education 2018), there are few recommendations within this document on how practitioners can do this. In this article I consider how geographical assessment methods could support practitioners to attend to the first two domains of Contextual Safeguarding - targets and legislative frameworks.

\section{Geographical approaches to crime and safety}

Since the earliest use of crime maps in the $19^{\text {th }}$ century, geographical methods have 
been utilised to document and map the locations of crime (Kindynis 2014). What these maps tell us, is that crime is not evenly distributed over space, but concentrated in particular locations- known as hotspots (Vandeviver and Bernasco 2017). Hotspot mapping is used to prevent a range of crimes including the reduction of violent crime such as homicides, aggravated assault and robberies (Ratcliffe et al. 2011). In relation to children, mapping exercises have supported responses to forms of adolescent harm by using police held data to inform efforts to prevent criminal exploitation of children (APPG on Runaway and Missing Children and Adults 2017). A number of geographical methods have explored children's experiences of safety. Firmin and Abbott (2018) used bus boarding data to map locations where children may be vulnerable to peer-on-peer abuse on bus routes. Pain et al. (2006) combined GIS hotspot data and community interviews to build contextualised approaches to fear of crime and street lighting. Community mapping was used by Winton (2007) in Guatemala to understand the impact of violence on children's mobility. In her work on photomapping, Teixeira (2018) highlights the opportunity of engaging GIS methods within social work.

Beyond locating where crime has occurred, spatial approaches have informed interventions used to prevent or respond to crime. Based on rational choice theory (Cornish and Clarke 2014), situational crime prevention utilises place-based knowledge to develop approaches to crime prevention that targets crime in specific locations (Clarke 1997). Situational crime prevention involves altering the environment so the risks of getting caught outweigh the benefits of committing the crime, deterring offenders. A subsidiary of rational choice theory, routine activities theory - like situational crime prevention - suggests that for crime to happen three elements are required: motivated offenders, suitable targets and the absence of suitable guardians (Cohen and Felson 1979). Reynald (2010) suggests there are 
three types of guardians. - handlers, who supervise potential offenders, managers who supervise places, and guardians who oversee potential targets.

Research on situational approaches provide insights into the types of methods that support assessment of places. Armitage and Monchuk's (2011) evaluation of a Secured by Design scheme used resident surveys and visual audits as part of their evaluation of housing estates. Visual audits measured signs of crime and disorder such as broken glass, graffiti, access etc. While children and young people to not often explicitly feature within this work Painter and Farrington's (2001) evaluation of a crime reduction scheme through increasing lighting did engage with young people. Using interviews and surveys young people were asked to self-report offences and their own experiences of victimisation before and after the lighting initiative.

In response to safeguarding children, situational models are being adapted in preventing child sexual abuse (Rayment-McHugh et al. 2015). While these efforts may include changes to the physical landscape to regulate access to children, or increasing guardianship (Wortley and Smallbone 2006), Smallbone and Rayment-McHugh (2013) developed approaches to preventing youth sexual violence and abuse that move beyond purely situational approaches. Their work explores the ecological context of sexual violence and seeks to prevent it through interventions in both the physical and situational aspects of crime and the broader social, cultural and political causes of harm.

If environmental approaches to crime are concerned with not only reducing incidences of crime, but also the fear of crime, then it important to consider how those leading such interventions engage with children and young people. This is a challenge when resources are often allocated on the basis of reported crime (Ludwig, Norton, and McLean 2017). Especially when we know that the majority of crimes to children go unreported to the police who may fear repercussions from adults and peers (Beckett and Warrington 2014). 
Critics of situational crime prevention, however, argue these approaches use a limited conceptualisation of space whereby methods to prevent crime represent a move towards exclusionary and enforcement - as opposed to social - practices of crime prevention (Darke 2011). Geographers have argued that efforts to 'design out' crime and fear through situational practices, fail to adequately explore the social and political causes of crime in different places (Koskela and Pain 2000). While this may be true, in this article I consider how the intersection of child protection, situational and geographical methods can expand the potential to reduce harm to young people. This article raises two questions:

- How does adopting geographical assessment methods enable child protection practitioners to better target the social conditions of harm?

- What difference does it make for child protection practitioners to do this work, as opposed to Community Safety partners?

\section{Methodology}

This article is based on an action-research study in one children and families social care service in England. The overall aim of the research was to develop, test and embed a Contextual Safeguarding system aimed at addressing extra-familial harm experienced by children and families. The project considered how child protection systems can respond to contexts as opposed to individual children and families. This article focussed specifically on three underpinning research aims:

- To increase the capacity of Children's Social Care to identify, assess and address risks of significant harm beyond families.

- Create tools and methods for intervening with, and managing, risk within peer groups or locational hotspots.

- Empower stakeholders to initiate and implement safeguarding responses. 
Consent for the research was granted by the University of Bedfordshire and the participating local authority's ethics board. To ensure confidentiality the research team accounted for anonymity, researcher and participant safety and the ethical analysis and dissemination of the data collected.

\section{The study}

Over a period of one and a half years the research team (formed of the Principle Researcher, a Research Assistant and an Embedded Researcher) sat within the project team within children and families social care (formed of five social workers, three practitioners, one analyst, one project manager and one administrator) to develop and test Contextual Safeguarding. As the Embedded Researcher I was based part-time in the project team. This role involved: observing and documenting current approaches to extra-familial harm, working with the project team to develop and test new systems and approaches (for example assessment methods, policies or interventions) and support dissemination through co-writing briefings, delivering training and strategic engagement. Here I draw upon ethnographic 'embedded' methods including:

- Field notes

- Observations of strategic and operational meetings

- Case file review

- Training facilitation to multi-agency practitioners

- Analysis of five context assessments (school assessment $n=1$, neighbourhood assessment $n=2$, peer group assessment $n=3$ )

- Observations of reflective sessions with practitioners across social care

- Fortnightly reflective sessions with the project team

- Observations of practice including surveys and neighbourhood observations

- Interviews with the project team, participating residents and social workers

- Observation of context conferences 
A result of this 'embedded' approach is that the research methods used, data captured and analysis do not fit traditional (linear) research approaches. For ease, I focus in this article on a case study: the process of developing and conducting a neighbourhood assessment over a seven month period (February -September 2018).

\section{Case study Neighbourhood assessment}

In order to 'increase the capacity of Children's Social Care to identify, assess and address risks of significant harm beyond families' the project team developed context assessments. Here I focus on a neighbourhood assessment. The assessment was triggered by concerns that an adolescent living in a housing estate was at significant risk of harm

The [Estate name] was highlighted as an area of concern following [...] information received from the Probation service which indicated that an adolescent living on the estate was the intended victim of a serious violent attack. Subsequently, video footage of Drill [music] videos filmed on the estate reinforced the vulnerability of the young person, followed by 2 serious violent incidents (stabbings) on the estate in close proximity to the home of the aforementioned young person. (Neighbourhood assessment notes)

Following the initial referral to one social care team to conduct an individual child and family assessment for the young person - named Tomas for anonymity- at risk, the project team were informed of the case. While normally only a child and family assessment would be conducted, as the case involved a significant extra-familial risk the team conducted a neighbourhood assessment. The activities conducted by the project team included:

- Review of all 11 case files held by Children's social care for children living in the estate

- Five neighbourhood observations of the estate over a period of 4 weeks 
- Community engagement through attendance at four community meetings (Tenants and Residents' Association, Local Regeneration Board, Neighbourhood Panel and Local Ward Forums), one weapons sweep and community walkabout.

- 23 residents surveys $-26 \%$ of which were completed by adolescents

- Interviews with local agencies including: Safer Neighbourhood Team and Police, Housing team, Integrated Gangs Unit, Tenants' Residents Association, two Youth work organisations, local businesses, one local school and one local doctor's surgery.

- One context conference (a multi-agency safeguarding meeting) to discuss the assessment and develop an intervention plan.

\section{Geographical assessment methods}

As part of the assessment, we co-created methods to facilitate assessments of extra-familial contexts. Two geographical assessment methods were developed (those which would facilitate understanding of the spaces under assessment).

- Safety mapping was developed by Nyarko (2018) from the project team to support practitioners to work with children to identify areas where they felt safe and unsafe. Safety mapping is a qualitative exercise which involves working with a young person to talk about, colour code or annotate locations and areas they feel safe and unsafe on a map (Nyarko 2018). As opposed to hot-spot mapping (which often relies on quantitative crime data), this exercise facilitates practitioners to understand young people's lived experiences of space.

- Secondly, through a series of neighbourhood observations: visits undertaken by the project team to observe the local area, identify evidence of risk, vulnerability or protective factors and to familiarise themselves with the local area. Evidence of risk and vulnerability included factors such as alcohol consumption, drug use, damaged 
buildings, poor visibility and natural surveillance. Protective factors included potential guardians, secure doors and CCTV. To support this work, an observations template was created based on the work of Reynald (2009) and Smallbone, RaymentMcHugh, and Smith (2013). Specific details were captured on handrawn or printed maps. A full overview of the method and template is available at Balci et al. (2018).

\section{Targets: Building practitioner knowledge of place}

Training on safety mapping was disseminated across children and families social care. While the primary purpose of safety mapping was to understand children's experiences in the local environment, through the process of using the tools, practitioners developed better knowledge of areas they worked within (Teixeira 2018):

If you work in the borough, how much of it do you know? If a young person is talking about a particular location like a park you need to understand where they are talking about. (Social worker, notes from training on safety tool)

As part of training, practitioners were asked to label a local map with area names. Of fifteen practitioners, no-one was able to completely label the map. The social worker leading the training suggested the importance of knowing the local area:

You need to understand what they are going through and where so you don't meet them in areas that are unsafe for them. Talk to your young person about where they feel safe. Sometimes the whole map is red. If there are no green [safe] places who are their green people? (Social worker, notes from training on safety tool)

Throughout the project the team ensured practitioners in the borough understood the areas they worked within. This included inviting presentations on gang territory and providing visible maps at meetings. There were benefits of this knowledge. Firstly, if children named specific areas, practitioners could understand where the location was and note down any 
details, secondly to ensure practitioners did not ask children to travel to areas for meetings where they felt unsafe.

In addition to safety mapping, neighbourhood observations supported practitioners to visit areas where children were encountering risk. While social workers already visited areas for meetings in the home environment, neighbourhood observations involved spending time specifically in the neighbourhood and using this knowledge to inform assessments. While practitioners did not necessarily observe harm happening, it did allow them to put reports of harm into context and to consider interventions. Following reports of sexual exploitation and drug use in a stairwell two practitioners visited the site:

We didn't actually see any harm happening there but it did help us understand how it could happen. The whole stairwell was blocked up so there was no light. There were no exits or natural supervision because it was cut off from the road. (social worker reflection)

Within the neighbourhood assessment, Tomas' social worker was supported to use both the safety mapping exercise with Tomas and to carry out neighbourhood observations:

It was helpful to have someone offer to go outside, to go into the community. We saw the community centre but it had newspaper on the floor, all these children that are hanging around making music videos. (Interview with social worker)

As a result of visiting the area over time and familiarising themselves with local residents the practitioners developed a better understanding of the estate. These findings were used to inform the assessment:

The impact of the regeneration of the area, specifically empty properties and high fencing [...]Some suggestions have also been made regarding access, specifically vehicle access, to [area], and access to the roof via the stairwell in [area]. Further consideration will need to be given to the impact that limiting access or re-directing the flow of traffic on the estate would have on safeguarding the community as a whole. (assessment report) 
Building practitioner understanding of the areas they worked within was key to ensuring interventions were appropriate for the community living there and recognised children's lived experiences of spaces.

\section{Targets: Understanding spaces}

While mapping techniques were already in use by the Police, Community Safety and analysts in the research site to hotspot crime data these methods were not directly used by social workers. Within the neighbourhood assessment one practitioner visited the location five times for the purpose of observation. Through the process of visiting, walking through and observing the local environment she discussed how visiting allowed her to become familiarised with the area and engage with residents. This practitioner suggested the observation template prompted her to note details of the local environment, for example, who was using the area, what activities were occurring and potential guardians.

If we hadn't visited we wouldn't have been able to come up with our hypothesis as to why the children were hanging around there. We think, because they have access to the roof, and because there are number of exit ways and rat runs they have a better visibility of cars entering the area, and routes to leave if needed. We realised that perhaps this estate is safer than those surrounding it for children. (notes from reflection meeting)

This information supported the practitioner to consider interventions with children's experiences in mind to develop multi-faceted understandings of space. Following from Soja (1996) this allowed practitioners to account for 'perceived' space and 'lived space'- on one visit the practitioner used a map of the local area to chart aspects of the physical environment including visible CCTV, lighting, and access and exit points. The practitioner then gave this map to the social worker allocated to a young person living in the area to ask them how they used the space and what changes they would make to the physical environment to make it safer. 
In addition, the safety mapping exercise supported children to use their own knowledge, expertise and experience to define where they felt safe and unsafe as opposed to relying on practitioner representations of 'conceived' space (Lefebvre and Nicholson-Smith 1991). For Tomas this provided an opportunity to discus his experiences:

[young person] does not feel safe travelling through [area name] (even the areas he identifies as Green), and gets cabs to travel through the borough. (Child and family assessment notes)

The mapping exercise facilitated the opportunity to explore young people's lived space. Through drawing upon his knowledge of first space - by using a map to draw and mark boundaries - and second space - through discussions of how different areas were represented and imagined (such as gang territories) the mapping exercise created opportunities to explore his lived space. Through mapping Tomas suggested he felt unsafe in several areas, because of the influence of rival gangs: 'He even felt unsafe in places he shouldn't [feel unsafe] because of the gangs there' (interview with social worker). This was then the basis for the social worker to build a more nuanced picture of why they might feel safe and define safety and risk from the perspective of the young person.

Furthermore, safety mapping supported practitioners to understand the links between children. This was particularly important for identifying children at risk of exploitation. One social worker discussed how they used the mapping tool to identify where young people were at risk of grooming for drugs trafficking by exploring which young people were linked and where they socialised:

She [social worker] was able to ask lots of questions about friends. We know about [name] road so we keep asking about it and adding to it [on the map]. We know the friends are doing county lines [criminal exploitation involving drugs trafficking] but no one knows where that is to. (interview with social worker) 
Through mapping the social worker suggested the children 'felt important' and discussed their experiences. Two maps were annotated with the following based on the children's experiences with locations marked as safe and several areas marked as 'opps' (oppositional gangs):

Don't go there, don't know anyone around

Go there, need to be careful Going to [road name]

Don't go and can still go there, safe to go.

Can't go everywhere. Not in gang if was would have already been stabbed. (safety map extracts)

For children affected by criminal exploitation this highlighted the constricted nature of their experiences of place and allowed the social workers to consider which young people were linked and where they spent time.

\section{Child protection approach}

In addition to understanding the locations young people were at risk, findings evidenced the benefits of doing so from a child protection lens. Furthermore they findings highlight the necessity of understanding space in multiple ways. While speaking with children about places illuminated the ways that representations of spaces - such as gang territory - shaped their experiences of space, different agencies had the capacity to shape and impact the physical built environment.

Within the neighbourhood assessment, as the area was undergoing regeneration, changes to the physical landscape were being considered by the regeneration team and Community Safety to reduce the impact of crime in the area. The project team suggested changes by external partners were not always in accordance of the needs identified by the social care team: 
Due to the regeneration of the area, changes are currently being made to the physical space, such as a high perimeter fence being placed through the centre of the communal green space, which may limit access and visibility (neighbourhood assessment)

By speaking with residents, the project team identified that while the fence reduced access to an area it also reduced the visibility for the residents.

There was a blind spot when the walls came up around the regeneration area. Some of the tenants got their own little drug business from their own flats and that is bringing quite a lot of strangers on the estate. (Tenant's association, Neighbourhood meeting)

All teams were worried about the ability of cars to enter the estate and access by foot due to concerns that other children were entering to incite violence. As such discussions were in process to change the traffic flow and block off some entry routes. However, through a combination of observations, visits to the neighbourhood and safety mapping with children the project team raised concerns about interventions inadvertently reducing the safety of children. In one meeting, practitioners discussed potential changes to the physical landscape:

[Social worker] has raised concerns that planned changes to the estate might increase the vulnerability because while it may reduce entry points it could also reduce the number of exit routes for children. (meeting observation)

Instead of imposing situational crime prevention approaches to targeting specific concerns from the perspective of adults, the team planned to utilise mapping exercises with children locally. As such it was decided further work would need to be undertaken to see how the children used the space and what changes they felt would increase safety or feelings of safety.

While it was important for the social care team to consider space in this way, they were not the only agency working there and did not, on their own, have capacity to act on all information or make changes to the estate. Several system challenges emerged through the 
process including the challenge of competing priorities and approaches used by agencies. Furthermore information gained through engaging children was not always valued:

'children were telling us that [area] was a problem. We didn't do anything. Then two incidents [one murder and one stabbing] happened. We're not listening to that soft intelligence'. (Meeting observation)

Additionally, the focus of the child protection system itself, acted as a barrier for practitioners working in this way. While the level of risk for Tomas was high his social worker reflected on what may have happened normally (without the project):

\footnotetext{
'it [geographical assessment methods] provided me a more in-depth analysis. Normally we'd just close it because he's 17, because we've run out of things to do' (interview with social worker)
}

In combination, safety mapping and neighbourhood observations supported social workers to consider the spaces in different ways - attentive to children's experiences of space rather than adult conceptualisations of their use of space.

\section{Discussion}

The current child protection system is focussed on harm caused by the family or within the family. When harm is outside of the home it often does not meet a threshold for statutory intervention - despite the level of harm - because social workers do not have tools or methods to identify it (Lloyd and Firmin, forthcoming). For example, even if the primary threat to a young person is in a park or on a bus route, the predominant methods focus on visiting the family home. In the research presented here, despite the level of harm Tomas was faced with, the case would have been closed because of his age and because the family were supporting him. While the research presents only the initial stages of embedding geographical assessment methods, as Contextual Safeguarding becomes adopted, social workers will need 
support to identify and assess harm in different locations - these methods provide an opportunity to do so.

At the start of this article I posed two questions: how does adopting geographical research methods enable social workers to better target the social conditions of harm? And what difference does it make for social workers to do this work, as opposed to community safety? While Contextual Safeguarding brings the target - extra-familial contexts - within a child protection legislative framework (figure one), geographical methods provide a means to assess and intervene within the locations where young people experience harm - regardless of location. Secondly, the harm young people experience outside the home, such as that experienced by Tomas constitutes child abuse, uniting these areas ensures that the legislative framework used, is that which was designed to protect young people from harm - by people trained to employ it.

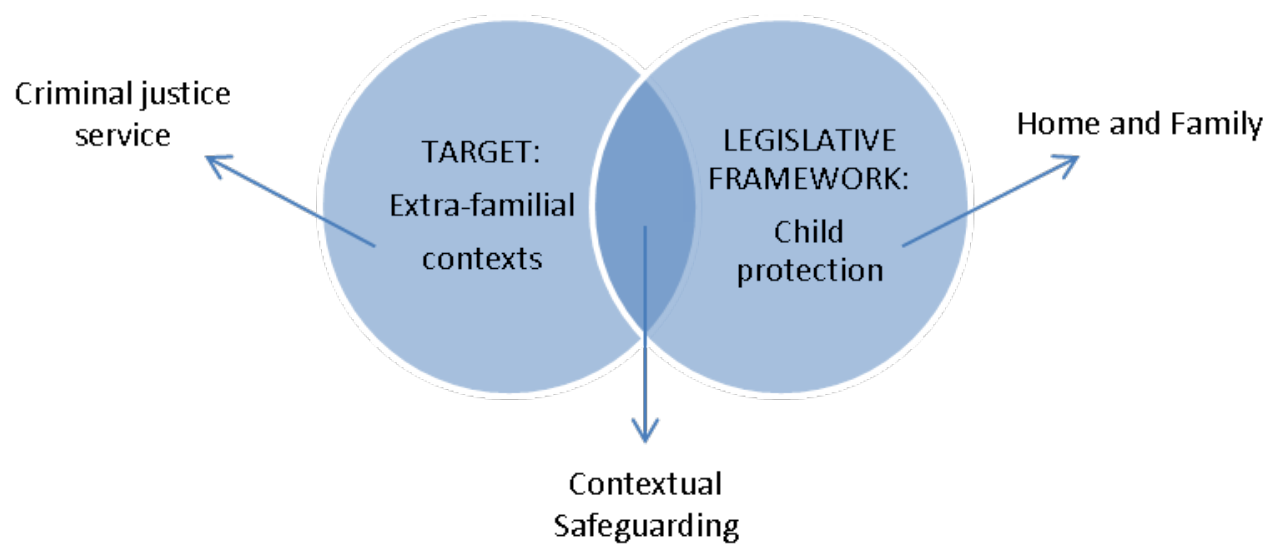

Figure one: Target and legislative framework within Contextual Safeguarding

Utilising these methods has a number of challenges. The current assessment framework presented in Working Together (Department for Education 2018) focuses on the child and family. To ensure effective interventions into extra-familial spaces requires assessment frameworks that prioritise aspects of contexts within and outside of the home. In the case of this neighbourhood assessment findings from the mapping and observations 
formed one part of the assessment process. To support this work an assessment framework was developed. As Figure Two below shows, these assessment methods supported the team to consider a range of factors such as guardianship capacity, environmental and community factors and young people's experiences of the neighbourhood space.

\author{
Insert Figure Two
}

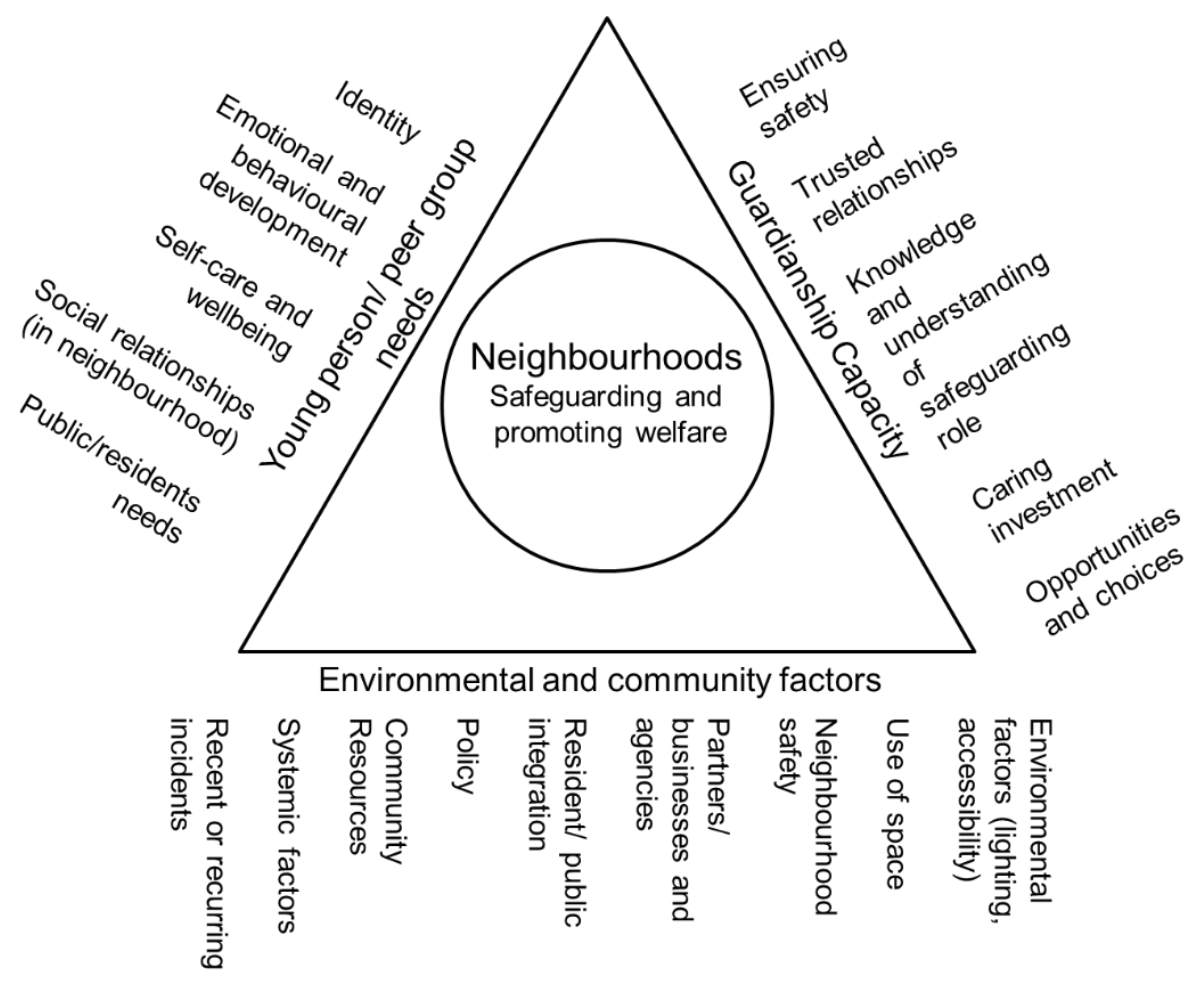

Figure Two: Neighbourhood assessment framework (Lloyd et al. 2018)

Assessing in this way allows practitioners to identify harm but also potential interventions into those spaces. Aligning to traditional child protection frameworks, following the assessment the findings were presented in a context conference. Like a child protection conference multi-agency professionals associated to the context attended to review the assessment and develop a plan. However, currently there is no legal basis which requires multi-agency partners to support interventions highlighted through the process of context 
assessment. Ultimately, the six context assessments and conferences conducted throughout the project required relationships and the good will of partners to make the changes required. Across England we are seeing place-based assessments conducted in an ad-hoc way. Broader questions need to be asked about the validity of current policy which makes suggestions about working contextually but make few recommendations as to how. If practitioners are required to work in this way then they require policy, training and resources that supports this work.

This articles, follows others (Firmin Forthcoming) to raise the question of whose role it is to protect children from significant harm outside of their homes? In asking social workers to work in this way are we in fact requiring them to do the work of Community Safety? Currently in England Community Safety Partners are not primarily tasked to provide welfare responses to children affected by extra-familial harm. While they certainly hold an important role, the thresholds for Community Safety (the reporting of crime) and social care (when a child is at risk of significant harm) are different. When children are harmed in their families, rarely is it in their best interest to pursue criminal convictions of those families. The same can be said of harm outside of families. By leading with social care we send a message to young people and the communities they live in that this is about protecting and promoting their welfare and not solely the prevention of crime. Although this article suggests this methods could be used by social workers they are not restricted to one agency. As Contextual Safeguarding develops nationally we are likely to see variations in how it is utilised and which agencies are drawn into this response. The answer to whose role it is and which agencies are best able to protect children will emerge as these approaches develops. While working in this way does indeed signal a shift in the target of social work, it aligns strongly with the focus of their work - to protect children from harm - wherever that harm may be. 


\section{References}

APPG on Runaway and Missing Children and Adults. 2017. Briefing report on the roundtable on children who go missing and are criminally exploited by gangs.

Armitage, Rachel, and Leanne Monchuk. 2011. "Sustaining the crime reduction impact of designing out crime: Re-evaluating the Secured by Design scheme 10 years on." Security Journal 24 (4):320-343.

Balci, M., Burke, C. and Lloyd, J. (2018), "Neighbourhood observations”, available at: www.contex

tualsafeguarding.org.uk/assets/documents/Neighbourhood-Observations.pdf (accessed 27 November 2019).

Beckett, Helen, and Camille Warrington. 2014. Suffering in silence: Children and unreported crime. Victim Support/University of Bedfordshire.

Clarke, Ronald Victor Gemuseus. 1997. Situational crime prevention: Criminal Justice Press Monsey, NY.

Cohen, Lawrence E, and Marcus Felson. 1979. "Social change and crime rate trends: A routine activity approach." American sociological review:588-608.

Cornish, Derek B, and Ronald V Clarke. 2014. The reasoning criminal: Rational choice perspectives on offending: Transaction Publishers.

Darke, Sacha. 2011. "The enforcement approach to crime prevention." Critical social policy 31 (3):410-430.

Department for Education. 2018. Working Together to Safeguard Children. HM Government.

Featherstone, Brid, Karen Broadhurst, and Kim Holt. 2011. "Thinking systemicallythinking politically: Building strong partnerships with children and families in the context of rising inequality." British Journal of Social Work 42 (4):618-633.

Firmin, Carlene. 2017. Contextual Safeguarding: An overview of the operational, strategic and conceptual framework.

Firmin, Carlene, and Matthew Abbott. 2018. "A Route to Safety: Using Bus Boarding Data to Identify Roles for Transport Providers within Contextual Safeguarding Systems." Children \& Society.

Kindynis, Theo. 2014. "Ripping up the MapCriminology and Cartography Reconsidered." The British Journal of Criminology 54 (2):222-243. doi: 10.1093/bjc/azt077.

Koskela, Hille, and Rachel Pain. 2000. "Revisiting fear and place: women's fear of attack and the built environment." Geoforum 31 (2):269-280.

Lefebvre, Henri, and Donald Nicholson-Smith. 1991. The production of space. Vol. 142: Oxford Blackwell.

Lloyd, J. and Firmin, C. ( forthcoming), "No further action: contextualising social care decisions for children

victimised in extra-familial settings", Youth Justice.

Lloyd, J., Owens, R. and Firmin, C. (2018), "Context assessment triangles", available at: www.contex

tualsafeguarding.org.uk/assets/documents/Context-Assessment-Triangles.pdf (accessed 27 November 2019).

Ludwig, Anika, Mike Norton, and Iain McLean. 2017. Resource Allocation Processes in Policing in Great Britain: Chartered Institute of Public Finance and Accountancy London.

Merrifield, Andrew. 1993. "Place and space: a Lefebvrian reconciliation." Transactions of the institute of British geographers:516-531.

Munro, Eileen. 2011. The Munro review of child protection: Final report, a child-centred system. Vol. 8062: The Stationery Office. 
NSPCC. 2015. Assessing children and families.

Nyarko, S. (2018), "Safety mapping exercise", available at:

www.contextualsafeguarding.org.uk/en/

publications/safety-mapping (accessed 27 November 2019).

Pain, Rachel, Robert MacFarlane, Keith Turner, and Sally Gill. 2006. "'When, where, if, and but': Qualifying GIS and the effect of streetlighting on crime and fear." Environment and Planning A 38 (11):2055-2074.

Painter, Kate A, and David P Farrington. 2001. "Evaluating situational crime prevention using a young people's survey: Part II making sense of the elite police voice." British Journal of Criminology 41 (2):266-284.

Pitts, John. 2013. Reluctant gangsters: The changing face of youth crime: Willan.

Ratcliffe, Jerry H, Travis Taniguchi, Elizabeth R Groff, and Jennifer D Wood. 2011. "The Philadelphia foot patrol experiment: A randomized controlled trial of police patrol effectiveness in violent crime hotspots." Criminology 49 (3):795-831.

Rayment-McHugh, Susan, Dimity Adams, Richard Wortley, and Nick Tilley. 2015. "Think Global Act Local': a place-based approach to sexual abuse prevention." Crime Science 4 (1):22. doi: 10.1186/s40163-015-0035-4.

Reynald, Danielle M. 2009. "Guardianship in action: Developing a new tool for measurement." Crime Prevention and Community Safety 11 (1):1-20.

Reynald, Danielle M. 2010. "Guardians on guardianship: Factors affecting the willingness to supervise, the ability to detect potential offenders, and the willingness to intervene." Journal of Research in Crime and Delinquency 47 (3):358-390.

Smallbone, Stephen, Susan Rayment-McHugh, and Dimity Smith. 2013. "Preventing Youth Sexual Violence and Abuse in West Cairns and Aurukun: Establishing the scope, dimensions and dynamics of the problem."

Smallbone, Stephen, and Susan Rayment-McHugh. 2013. "Preventing youth sexual violence and abuse: Problems and solutions in the Australian context." Australian Psychologist 48 (1):3-13.

Soja, E. 1996. Thirdspace. Journeys to Los Angeles and other real-and-imagined places. Oxford: Blackwell Publishers.

Teixeira, Samantha. 2018. "Qualitative Geographic Information Systems (GIS): An untapped research approach for social work." Qualitative Social Work 17 (1):9-23. doi: $10.1177 / 1473325016655203$.

The Telegraph. 2018. "Child stabbings rise by 63pc amid 'disturbing' trend of younger knife crime victims." The Telegraph,, 11 April 2018.

https://www.telegraph.co.uk/news/2018/04/11/child-stabbings-rise-63pc-amiddisturbing-trend-younger-knife/.

Tuan, Yi-Fu. 1979. "Space and place: humanistic perspective." In Philosophy in geography, 387-427. Springer.

Vandeviver, Christophe, and Wim Bernasco. 2017. "The geography of crime and crime control." Applied geography 86:220-225.

Winton, Ailsa. 2007. "Using 'participatory'methods with young people in contexts of violence: reflections from Guatemala." Bulletin of Latin American Research 26 (4):497-515.

Wortley, Richard, and Stephen Smallbone. 2006. "Applying situational principles to sexual offenses against children." Crime prevention studies 19:7. 